\title{
Research on Effective Teaching Courses Planning for Environmental Literacy in Climate Change
}

\author{
Jyh-Harng Shyng* \\ Life Sciences College, Zhaoqing University, Zhaoqing city, Guangdong province, China \\ *Corresponding author: Jyh-Harng Shyng, hidosing@outlook.com
}

\begin{abstract}
The earth's environment has been affected by drastic changes in the weather and generally, countries have been vigorously promoting the implementation of environmental education. Through teaching designs from teaching theories with Taiwan's higher education general education curriculum; the general course of Sustainable Development and Climate Change, this study developed a multi-teaching model and used the two-stage teaching strategy of observation and action in a variety of teaching activities arranged in each week of the semester in order to gradually improve students' environmental literacy. The specific actions and cognitions of adjustment and mitigation are to achieve the teaching goal of cultivating the ability of environmental literacy among students in the course as well as obtain feedback from the questionnaires on teaching after the course. The multi-teaching model constructed by the institute would obviously help students to improve their learning effectiveness.
\end{abstract}

Keywords: Environmental literacy; Instructional design; Teaching model; Instruction methods; Effective teaching

Publication date: July 2021; Online publication: July 30, 2021

\section{Introduction}

Core literacy has the characteristics of "commonality" or "interdisciplinary." Therefore, the cultivation of core literacy projects is not only related to a specific discipline, but it can be promoted in different forms through various subjects. Higher education in the $21^{\text {st }}$ century should lead young students to face all kinds of crises under the extreme climate in order for them to understand the truth of the problems as well as to reflect on the responsibility and consciousness of environmental ethics.

The research results lay the foundation of teaching designs for the sustainable development of environmental literacy education and the general education curriculum of climate change in the future. The two purposes of this study are as follows: (1) To create a multi-teaching model for the Sustainable Development and Climate Change general course in higher education with multiple teaching and learning models as well as the integration of creative activity thinking and operational experience of teaching design; (2) To cultivate students' environmental literacy with the continuous optimization of teaching design and the verified examples where effective learning is used to evaluate students' harvest and feedback

\section{Research on teaching models and learning models}

Since the $20^{\text {th }}$ century, with the influence of scientific thoughts and the development of psychology especially behavioral science, people have realized that teaching is also science. Teaching does not only have a scientific basis, but it can also be studied with scientific methods ${ }^{[1]}$.

Instructional design refers to the process in which a teacher makes scientific plans and reasonable arrangements in addition to formulating the entire teaching process in advance for each link and element of 
the teaching process based on cognitive learning theory, educational communication theory, and system science theory according to the students' learning characteristics and their own teaching styles in order to optimize the teaching process and improve the teaching quality. It can be said that teaching design is an indispensable part of the teaching work and a blueprint to guide teachers for effective teaching ${ }^{[2]}$.

There are voluminous studies on instructional design. Many theories and opinions have been studied and defined along with many empirical studies that have been carried out. According to Pan Hongjian, Liu Hua, and Cai Cheng, the teaching model can provide models and procedures for the teaching of various subjects and it builds a bridge between theory and practice ${ }^{[1]}$. The use of a simplified form to express a teaching thought or theory makes it easy for people to master its use and it can effectively guide the teaching practice. The specific teaching experience is summarized to form an exploratory framework and through continuous practice and experiment, the theory is then further systematized and standardized to provide materials for the research of teaching theory.

Teaching model, teaching strategy, and teaching method are all part of the teaching design. Teaching rules need to be specific and operable. Teaching model includes teaching strategies in which they are related to but different from teaching methods. The relationship among teaching model, teaching strategy, and teaching method is an important practical process in the teaching design ${ }^{[4]}$.

In terms of the transformation stage or sequence from theory to practice, instructional design is in the order of "Theory of Instruction" $\rightarrow$ "Model of Teaching" $\rightarrow$ "Instructional Strategy" $\rightarrow$ "Instructional Method" $\rightarrow$ "Teaching Practice" [5].

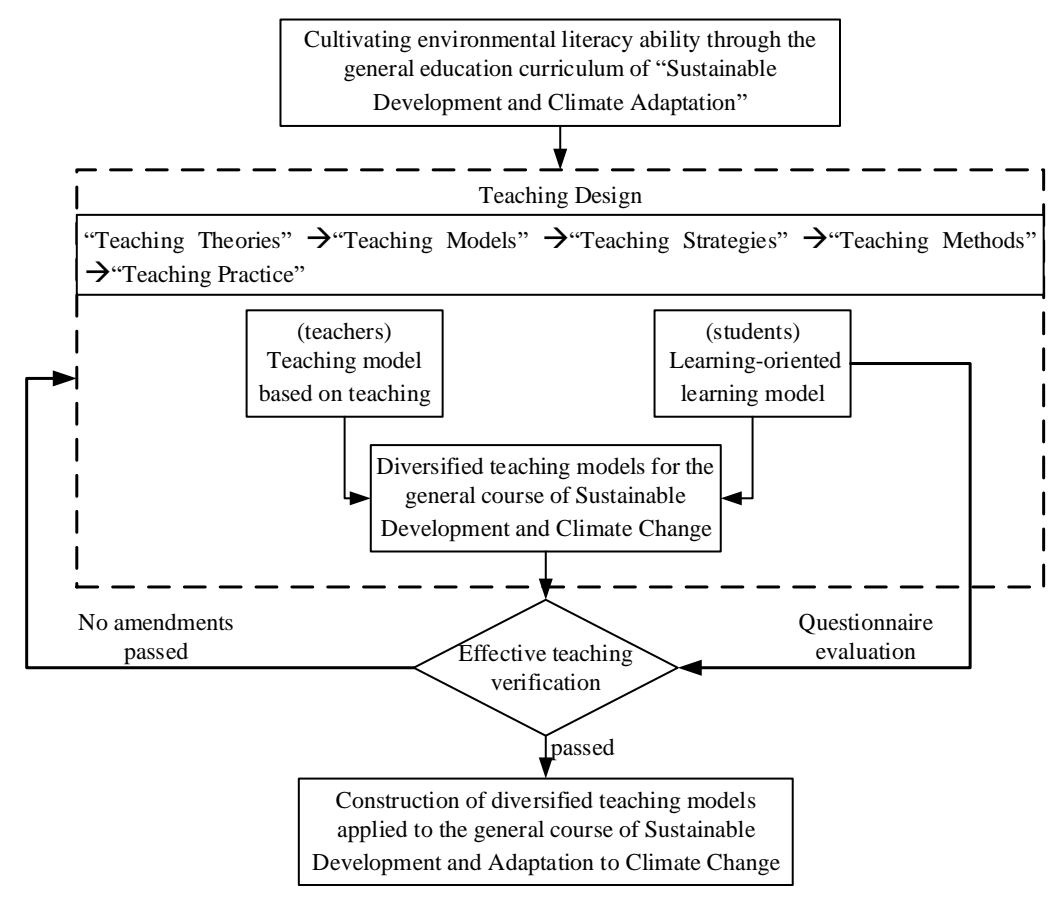

Figure 1. Concepts of this study

According to the above specific views, this study selected relevant studies on teaching models and learning models in order to construct the theoretical concept here. The related literature collection directions are as follows: (1) Teacher-oriented teaching models; (2) Student-oriented learning models; (3) To construct the specific principles of curriculum teaching with core literacy; (4) Theory of effective teaching. 


\subsection{Effective teaching}

Effective teaching means that after a period of teaching, teachers help their students in completing their learning tasks and achieving the expected progress and development, realizing the teaching objectives, and promoting the students' internal development and all-rounded development including the development of knowledge, intelligence, emotion, creativity, thinking, and practical ability ${ }^{[6]}$. That is to say, the students' progress or development is the only indicator of teaching effectiveness. Effective teaching is a modern teaching concept to improve teachers' teaching efficiency and to strengthen the process evaluation as well as the target management ${ }^{[7]}$.

To determine this teaching concept is to avoid side effects, reduce idle work, as well as to improve the pertinence, effectiveness, and strategy of education as well as teaching in the process of education and teaching. Effectiveness comprises of three aspects which are effectiveness, efficiency, and benefit ${ }^{[8]}$.

According to Lin Jihui and Zeng Youzheng, effective teaching is a modern teaching idea which takes the development of students as the center, emphasizes the guidance of quality education theory, pays attention to the effectiveness of teaching as well as the unity of teaching and learning, in addition to advocate the diversification and flexibility of teaching. The main purpose consists of three aspects which include to arouse students' learning intention and interest, to clarify teaching objectives, and to adopt teaching methods that are easy for students to understand and accept. It is believed that teachers can stimulate students' learning motivation where students would want to learn, be willing to learn, and happy to learn. Teachers should enlighten their students on "what to learn" and "how much to learn." The teaching discourse should be concise and clear while the teaching means should be advanced and suitable so that students can understand it clearly and easily. Teaching methods should also be flexible and diversified to meet the development needs of different students ${ }^{[9]}$.

\subsection{Constructing the specific principles of course teaching with core literacy}

The curriculum and teaching of core literacy can be integrated into various disciplines through appropriate textbooks or teaching methods as well as taking into account the "learning contents" or "learning performance" of the disciplines so as to promote the balanced integration of students' knowledge, skills, and emotional orientation.

Literacy-oriented teaching emphasizes the connection of context, the students' initiative and participation, as well as the integration of cognitive skills and emotions in addition to the possibility of being appropriately adjusted for different literacy projects. Therefore, the vast majority of field subjects and teaching units should be able to carry out quality-oriented adjustments.

Lin Yongfeng has put forth four basic principles which are the essentials of quality-oriented teaching design ${ }^{[10]}$ as a reference for quality-oriented curriculum and teaching design:

(1) Connecting with the actual context to make learning meaningful

(2) Emphasizing on students' participation and active learning to enhance their abilities

From the perspective of curriculum design, more attention should be paid to what the process model emphasizes such as the students' initiative, participation, attempt, exploration, discussion, respect, reflection, choice, etc.

(3) Considering the content (learning content) and process (learning performance) of learning so as to show that literacy is an integrated ability of knowledge, skills, and affection

(4) Different design focuses for different core literacy projects 


\subsection{Theory of teaching models based on teaching}

Teaching models refer to the paradigms of relatively stable, systematic, and theoretical teaching activities formed based on certain teaching ideas and theories ${ }^{[10]}$. Teaching models are the combination of teaching theories and practices where they are systematic generalizations of teaching experiences. They are not only formed directly from rich teaching practice experiences through theoretical generalizations but they are put forth as hypotheses which are formed after many experiments under the guidance of certain theories ${ }^{[11]}$.

\subsubsection{Classification of teaching models}

According to domestic and foreign scholars from different angles, they can be divided into three types which are theoretical, level, and bipolar series classification.

(1) Theoretical classification

Joyce and Will distinguished four types of teaching models according to their theoretical roots which include teaching models based on information processing, personality development, social communication, and behavior correction ${ }^{[12]}$.

(2) Classification by level

From the perspective of the relationship between teachers and students, $\mathrm{Wu}$ Yexian divided teaching models into three categories ${ }^{[13]}$.

(3) Classification according to the bipolar series segmentation

The specific practice of "Bipolar Series Segmentation Method" is to establish two comparable and extremely opposite teaching models first and then to divide the middle models quantitatively ${ }^{[14]}$. Wang Cesan divided the teaching models of bipolar series segmentation into three categories ${ }^{[15]}$.

\subsubsection{Structural elements of teaching models}

According to Fundamentals of Curricula and Teaching Theories, a complete teaching model should include five basic elements which are teaching guiding ideology, teaching objectives, operating procedures, teaching strategies, and evaluation.

\subsubsection{Characteristics of teaching models}

According to Fundamentals of Curricula and Teaching Theories, the teaching model should have five characteristics which are integrity, simplicity, directivity, operability, and openness.

\subsubsection{Functions of teaching models}

According to Fundamentals of Curricula and Teaching Theories, the teaching model has two functions, namely "mediating effect" and "methodological significance."

(1) The mediating effect of teaching models

An individual's special experience is transformed into the intermediary link of general theories which contributes to the enrichment and development of teaching theories. The mediating effect of teaching models is due to the simplification of some theories. Originating from practice, it is the result of optimization, generalization, and processing of certain specific teaching activities. Its operational framework has inherent logical relationship with theoretical significance ${ }^{[16]}$.

(2) The methodological significance of teaching models

For a long time in teaching research, people used to adopt a single rigid way of thinking, focusing on the use of analytical methods to study each part of teaching but neglecting the relationship 
between them. Otherwise, they used to stay in the abstract understanding of the relationship between the various parts, lacking teaching characteristics and operability. The research on teaching models guides people in exploring the interaction and diversified forms of various factors in the teaching process as a whole as well as grasping the essence and laws of the teaching process from a dynamic point of view. At the same time, it also has a certain role in promoting the strengthening of teaching design and the optimization of the teaching process ${ }^{[17]}$.

The research on teaching models is an innovation of teaching research methodology. A teaching model is a simplified way of expression of a certain theory. It can reflect the basic characteristics of the teaching theory on which it is based through concise symbolic symbols, schemata, and explanations of relations so as to facilitate people's understanding of a certain teaching theory. It is an intermediate link for abstract theories to play its practical function ${ }^{[18]}$.

\subsubsection{Methods of teaching models}

The relevant teaching methods should be included in the teaching model. The teaching methods in this course should be used to explain the implementation concept of the overall teaching model. The various teaching methods are: (1) Cooperative learning teaching method; (2) Role-play technique teaching method; (3) Collaborative teaching method; (4) Intuitive method; (5) Socialized teaching method; (6) Constructivist approach teaching; (7) Discussion method; (8) Guided discovery teaching; (9) Project teaching method; (10) Heuristic teaching method; (11) Conventional instruction method; (12) Web-based instruction method.

\subsection{Theories of student-centered learning model}

There are about five types of student-centered learning models including team-based learning (TBL), problem-based learning (PBL), case-based learning (CBL), lecture-based learning (LBL), and researchbased learning $(\mathrm{RBL})^{[19]}$.

\section{Constructing a teaching model for the general course of Sustainable Development and Climate Change}

The National Oceanic and Atmospheric Administration (NOAA) has stated that people should have climate literacy ${ }^{[20]}$. The basic learning connotation of climate literacy has been included in the standards of science education in the United States. In this research category, it is extended to be more broadly defined as environmental literacy of climate change. The specific literacy skills that are required include: (1) Understanding the basic principles of the earth's climate system; (2) Knowing how to assess reliable scientific information on climate; (3) Conveying climate change in a meaningful way; (4) Making wise and responsible decisions as well as take actions that can affect the climate.

\subsection{Design of teaching contents in the general education course}

It was carried out in the course of the semester in which it encouraged students to truly experience by doing hands-on practice as the goal of the course design. It was expected that students could take care of the natural environment in real life, understand the importance and efforts of the society on this issue in the era of climate change, as well as adopt the teaching design principle of "being creative, combining with the environment, and aiding environmental protection by hand" in school life learning activities.

The teaching activities that were included in the course design were "making a semester learning experience handbook," "watching and learning multimedia videos," "keynote speeches by experts," 
"drawing up an earthquake and disaster prevention drill map," "visiting green building education demonstration base," "making environmental microfilm," and "interacting using Moodle network teaching platform" along with the learning manual assignments.

The contents of the teaching design in the general course of Sustainable Development and Climate Change were as follows: (1) Watching and learning multimedia videos; (2) Experts' keynote speech discussion; (3) Drawing a map for earthquake and disaster prevention drill; (4) Visiting green building education demonstration base (Beitou Branch of Taipei City Library).

Overall, there were three expected results of the students as follows:

(1) Conceptual cognition orientation

The cognition of cherishing the conservation and recycling of natural environmental resources, the specific concept of disaster prevention in daily life, as well as the further observation and recognition of the conservation and recycling of environmental resources.

(2) Practicing orientation

Increasing the practice activities according to the requirements of assignments and using creativity and practice to personally understand the on-site teaching process of environmental education and disaster prevention education.

(3) Personal experience orientation

Personally entering the green building environment to experience the specific effects of environmental protection through contact, learning, implementing, understanding the era of climate change step by step, and to think of how the members of the modern society view the ongoing environmental protection actions in life adjustment.

\subsection{Teaching strategies under the teaching mode of the general education course}

\subsubsection{Observation stage teaching strategy: Introduction to midterm examination (week 1 to week 9)}

Firstly, the course design before midterm exam introduced the relevant course requirements and overview of lecture contents so that students would understand the introduction of the earth's natural environment and the impact of natural disasters in addition to the challenges of disaster prevention in the geographical environment of Taiwan. The mid-term plan of the course focused on the adaptation of urban disaster prevention under climate change with wind and flood as the main contents so that students would understand the impact of natural disasters on the environment of Taiwan but the unique geographical environment of Taiwan can turn the impact of disasters into another possibility of recycling.

Therefore, the first expert lecture was carried out in which the theme was The Adaptation of Urban Disaster Prevention under Climate Change. Professor Wu from Mingchuan University was invited to make a speech. Next, the students learnt about the impact and influence of windstorms on the environment through multimedia teaching and how to use new technology and information to cope with the dramatic changes brought by windstorms.

The "escape map of campus earthquake and disaster prevention drill" was drawn during the mid-term and it inspired students to learn the connection between natural disasters and the campus in daily life as well as to make creative ideas.

\subsubsection{Action stage teaching strategy: Midterm observation to final session (week 10 to week 18)}

The course design after the midterm examination was "visiting green building education demonstration base." A multimedia course on green building, flood, and water application was planned in addition to the second expert lecture on Environmental Issues and Practices in Taiwan after the Visit. Professor Fan was invited to provide a lecture so that the students would have a better understanding of the environmental 
issues in Taiwan and think about the next steps in environmental education.

In the later stage, the third expert lecture was carried out. The theme of the lecture was The Specific Actions of Environmental Conservation and Practice under the Theme of Sustainable Development. Lin, the managing director of Lvxin Technology Group Co., Ltd. was invited to give a speech so that the students would understand how to effectively improve the quality of the environment by environmental conservation.

\subsection{Teaching methods applied throughout the semester}

Application of teaching methods throughout the semester:

(1) Learning experience and results manual

At the beginning of the class, each student was given a copy of the book. At the end of the weekly multimedia teaching observation, the students wrote their experiences from the lessons and specific suggestions into the learning experience and results manual which was collected and arranged by the course assistants. Students were able to enhance their memory of the teaching contents and improve their learning effect. The teaching methods used were the traditional teaching method and the construction teaching method.

(2) Network teaching platform

The teaching methods used in students' homework interactive learning were the discussion teaching method and the digital teaching method.

The planning theme of the semester course was based on observation and action while the teaching contents were based on adaptation, technology, and prevention countermeasures in terms of environmental protection, low-carbon homes, and renewable energy. The learning model designed for students comprised of LBL (5 weeks), PBL (4 weeks), CBL (1 week), TBL (2 weeks), RBL (3 weeks). The teaching strategy was to enable students to understand the quality of sustainable environment and to learn about how individuals respond to environmental changes while making the most appropriate adjustment behavior. The teaching strategy was divided into two stages, namely the observation stage and the action stage.

\section{Evaluation of the learning effectiveness of the multi-teaching mode}

According to statistics and sorting, the students involved were majoring in business administration, international trade, visual communication, information management, applied Japanese, and applied English. Among these students, the proportion of female was $69 \%$ whereas male was $31 \%$.

The ten teaching topics of this course were saving the earth's environment, natural disaster characteristics, earthquake disaster, urban disaster prevention and adjustment, wind disaster, green building concept, green building off-campus visit, environmental issues practice speech, environmental protection and green industry, environmental conservation practice speech, etc. The results of the survey on the learning achievement and academic performance of the ten topics were analyzed as follows:

(1) Reliability analysis: Cronbach's alpha value of 0.874 indicated that the ten topics had significant impact on students' understanding of the objectives of the course which also indicated that the curriculum was well-planned.

(2) Using student achievement as the controlled variable and learning achievement of the ten teaching topics as the independent variable, the regression analysis showed R-squared of $0.58(>0.5)$ (F test was 3.347; significance was 0.003). This can be regarded as an acceptable regression model.

According to the scoring standard, the average score of the students was 86.4. The students had a positive attitude toward learning and had gained a lot. According to the analysis of the situation of the questionnaire return suggested by the teaching evaluation, the frequency distribution, and the subject of each course, "productive" was the highest. The preliminary analysis is shown in Table 1. 
Table 1. Students' feedback after the implementation of the course

\begin{tabular}{clccc}
\hline No. & Topics & Mean value & Standard deviation & Description* \\
\hline 1 & Saving the earth's environment & 3.43 & 1.67 & $44.9 \%$. \\
2 & Natural disaster characteristics & 2.92 & 1.91 & $53.1 \%$. \\
3 & Earthquake disaster & 2.98 & 2.07 & $73.5 \%$. \\
4 & Urban disaster prevention and adjustment & 3.49 & 1.66 & $75.5 \%$. \\
5 & Wind disaster & 3.16 & 1.98 & $73.5 \%$. \\
6 & Green building concept & 3.33 & 1.89 & $73.5 \%$. \\
7 & Green building off-campus visit & 2.98 & 1.89 & $85.7 \%$. \\
8 & Environmental issues practice speech & 3.08 & 1.89 & $79.6 \%$. \\
9 & Environmental protection and green industry & 2.67 & 2.04 & $85.7 \%$. \\
10 & Environmental conservation practice speech & 2.02 & 2.12 & $89.8 \%$. \\
\hline
\end{tabular}

*Among the learning gains, "productive" was the highest

On the whole, the results of the ten activities showed a good correlation between the degree of achievement and the results of the semester. The multi-pedagogical model of this course can be regarded as an effective teaching model and can be used as a reference for continuous course optimization in future semesters.

\section{Conclusion and suggestions}

With the objective of cultivating students' environmental literacy in the general course of Sustainable Development and Climate Change, the instructional design was based on the above teaching theory to develop a multi-teaching model. The two-stage observation and action teaching strategies were used to arrange different teaching activities in the teaching content of each week of the semester. The purpose of this study was to enable students to gradually acquire the specific actions and cognition of adaptation and mitigation in environmental literacy through different learning modes.

As for teaching demonstration, this study had conducted a questionnaire survey on students who had selected courses and analyzed the feedback opinions of direct and effective teaching outcomes. The empirical results showed that the instructional design of this course still achieved better learning results. Hence, the instructional design of the multi-teaching model constructed in this study could achieve the purpose of cultivating environmental literacy. This study proposes that the sustainable improvement and revision of environmental education teaching for higher education students in the future would become a basic part of environmental education for the society in addition as an important sustainable project for the improvement of the earth's environment.

\section{Disclosure statement}

The author declares that there is no conflict of interest.

\section{References}

[1] Zhu H, Xu Y, Qi X, et al., Practical Research on the "Autonomous-Guided" Learning Model of English in Elementary and Middle Schools. China Wisdom Engineering Research Association Basic Education, "Thirteenth Five-Year Plan" Project Meeting.

[2] Zhan Y, Wang F, Li C, 2012, Education, Renmin University of China Press. 
[3] Pan H, Liu H, Cai C, 2012, Basics of Curriculum and Teaching Theory, Jiangsu University Press, Zhenjiang.

[4] Liu S, Research on the Status Quo of Autonomous Learning and Guidance Strategies of Rural Junior Middle School Students. Guangzhou University.

[5] Modern Curriculum Network, 2019, What are Teaching Methods, Teaching Models, and Teaching Strategies? What is the Difference between the Three? What's the Contact? From: https://twgreatdaily.com/_W5ipWwBvvf6VcSZUSUg.html

[6] Chen L, Exploration and Practice of Effective Teaching of Basic Mathematics for the " $2+4$ " Elementary Education Major at the Starting Point of Junior High School. Ludong University.

[7] Lin J, Zen X, 2007, Research on the Effective Teaching Characteristics of University Teachers. Curriculum and Teaching, 10(40): 31-47.

[8] Wang X, Research on Effective Teaching of High School Art Appreciation Course under the Background of New Curriculum Reform. Yanbian University.

[9] Tang Y, 2012, Research on Improving the Effectiveness of Primary School Science Classroom Teaching. New Campus: Learning Edition, 000(005): 117-9.

[10] Lin Y, 2017, The Curriculum Teaching Transformation and Design of Core Literacy, Educational Research Monthly.

[11] Bai X, Research on the Theory and Practice of Physics Independent Inquiry Teaching Mode. Shaanxi Normal University.

[12] Fang K, 2003, Teaching Principles and Methodology, Shanghai Literature and Art Publishing House.

[13] Wu Y, 1988, A Brief Talk on Classroom Teaching Mode. Educational Research and Experiment, (01): $12-5$.

[14] Huang J, Wang C, 1996, Modern Education Theory, People's Education Press, Beijing.

[15] Wang C, 2000, Teaching Review, People's Education Press, Beijing.

[16] Zhao X, Research on the Teaching Mode of General Technology Course. Capital Normal University.

[17] Li M, Research on the Teaching Mode of Ideological and Political Courses in Colleges and Universities. Central China Normal University.

[18] Sun A, Research on the Inductive Model of Mathematics Teaching under the Constructive View. Northwest Normal University.

[19] Antlong, 2018, Teaching Mode: TBL, CBL, PBL, RBL, LBL, xBL. https://kknews.cc/zh-tw/education /mqaro5z.html

[20] NOAA, 2009, Climate Literacy - The Essential Principles of Climate Sciences. http://www.globalchan ge.gov/ 